\title{
EVALUASI PRAKTIKUM BOTANY PHANEROGAMAE DENGAN MENGGUNAKAN MODEL CSE-UCLA (Studi pada Mahasiswa Jurusan Tadris Biologi Institut Agama Islam Negeri Kerinci)
}

\author{
Emayulia Sastria \\ Jurusan Tadris Biologi Fakultas Tarbiyah dan Ilmu Keguruan IAIN Kerinci \\ Jl. Kapten Muradi, Kecamatan Sungai Liuk, Kota Sungai Penuh. Propinsi Jambi, \\ 37112. Telp: (0748) 21065, website:www.iainkerinci.ac.id \\ Email: emayuliasastria@gmail.com

\section{Novinovrita} \\ Jurusan Tadris Biologi Fakultas Tarbiyah dan Ilmu Keguruan IAIN Kerinci \\ J1. Kapten Muradi, Kecamatan Sungai Liuk, Kota Sungai Penuh. Propinsi Jambi, \\ 37112. Telp: (0748) 21065, website:www.iainkerinci.ac.id \\ Email: novibio3@gmail.com

\section{Arif Maulana} \\ Jurusan Tadris Biologi Fakultas Tarbiyah dan Ilmu Keguruan IAIN Kerinci \\ Jl. Kapten Muradi, Kecamatan Sungai Liuk, Kota Sungai Penuh. Propinsi Jambi, \\ 37112. Telp: (0748) 21065, website:www.iainkerinci.ac.id \\ Email: arifmaulana2511@gmail.com

\section{Devie Novalyan} \\ Jurusan Tadris Biologi Fakultas Tarbiyah dan Keguruan UIN STS Jambi \\ Jl. Jambi -Muaro Bulian KM 16 Simpang Sungai Duren Kabupaten Muaro Jambi, \\ 36363. Telp: (0741) 583183-584118, , website:www.iainjambi.ac.id \\ Email: devienovallyan@gmail.com
}

\begin{abstract}
Abstrak
Salah satu cara yang dilakukan untuk memaksimalkan fungsi praktikum yang dilaksanakan dalam perkuliahan adalah melalui evaluasi program praktikum. Selama ini tidak pernah dilakukan evaluasi pada praktikum, yang terjadi hanya terfokus kepada pelaksaan praktikum itu sendiri. Ada banyak model evaluasi program yang dirancang oleh para ahli, model-model tersebut cenderung dikembangkan sesuai dengan tujuan pelaksanaan evaluasi salah satunya adalah model evaluasi program CSE-UCLA. Penelitian ini bertujuan untuk mengetahui system assesment, program planning, program implementation dan program certification praktikum Botany phanerogamae mahasiswa jurusan tadris biologi IAIN Kerinci. Penelitian ini termasuk kedalam kategori penelitian kualitatif yang termasuk jenis metode studi kasus (case study). Untuk mendapatkan data model CSE-UCLA ini peneliti menggunakan studi (1) observasi, mengamati pelaksanaan praktikum Botany Phanerogamae, (2) wawancara, ketua jurusan, dosen pengampu, asisten praktikum dan mahasiswa, (3) dokumen, data tentang visi dan misi Jurusan, kerangka kualifikasi nasional indonesia Jurusan Tadris Biologi, tujuan praktikum yang terdapat di dalam penuntun praktikum Botany Phanerogamae, dan struktur organisasi Jurusan Tadris Biologi. Hasil yang didapat, pada tahapan system assessment penilaian sudah dimiliki dan dilaksanakan, walaupun terdapat kendala
\end{abstract}


pada kurangnya perhatian mahasiswa terhadap lingkungan. Pada tahap program planning ini terfokus pada evaluasi terhadap kelayakan bentuk struktur organisasi Jurusan Tadris Biologi, evaluasi terhadap kesiapan kemampuan dosen dan asisten, saran dan prasarana serta pengelola labor dalam praktikum Botany Phanerogamae sudah dikatagorikan siap. Pada tahap program implementation sudah dilaksanakan dengan baik dan juga terstruktur. Pada program Improvement sudah dikategorikan efektif. Pada tahap program certification ini sudah berjalan dengan efektif dan sesuai dengan harapan dari Jurusan Tadris Biologi Institut Agama Islam Negeri Kerinci.

Kata Kunci: System assesment, program planning, program implementation, program certification dan Botany phanerogamae.

\begin{abstract}
One of the ways to maximize the practicum function carried out in lectures is through the evaluation of practicum programs. So far there has never been an evaluation on practicum, which only focuses on the implementation of the practicum itself. There are many program evaluation models designed by experts. These models tend to be developed in accordance with the objectives of evaluation. One of which is the CSE-UCLA program evaluation model. This study aims to find out assessment systems, program planning, implementation programs and certification program at Botany phanerogamae practicum for students of the tadris biology department, IAIN Kerinci. This research belongs to the category of qualitative research which includes the type of case study method. To get the CSEUCLA model data, researchers used studies (1) observation, observed Botany Phanerogamae practicum, (2) interviews, department heads, lecturers, practicum and student assistants, (3) documents, data about the vision and mission of the Department, Indonesian national qualification framework Biology Department, practicum objectives contained in the Botany Phanerogamae practicum guide, and organizational structure of the Department of Biology. The results obtained, at the stage of the assessment system the assessment has been owned and implemented, even though there are obstacles to the lack of student attention to the environment. At the program planning stage, it focused on evaluating the feasibility of the organizational structure of the Department of Biology, evaluating the readiness of the ability of lecturers and assistants, advice and infrastructure as well as the labor manager in the Botany Phanerogamae practicum. At the stage of the program implementation has been carried out well and also structured. The Improvement program has been categorized as effective. At the stage of the certification program it has been running effectively and in accordance with the expectations of the Department of Biology of the Kerinci State Islamic Institute.
\end{abstract}

Keywords: System assessment, program planning, implementation programs, program certification and Botanical phanerogamae. 


\section{PENDAHULUAN}

Praktikum merupakan bagian yang tidak terpisahkan dari pembelajaran sains termasuk Biologi. Hal ini menjadi dasar IPA juga sering disebut sebagai experimental science (Rustaman, 2006). Ada empat alasan pentingnya kegiatan praktikum. Pertama, praktikum dapat membangkitkan motivasi belajar. Kedua, praktikum mengembangkan keterampilan dasar melakukan eksperimen. Ketiga, praktikum menjadi wahana belajar pendekatan ilmiah. Keempat, praktikum menunjang materi pelajaran. Keterampilan proses sendiri meliputi: mengamati, menafsirkan, mengklasifikasikan, menggunakan alat dan bahan, menerapkan konsep, merencanakan percobaan, berkomunikasi dan mengajukan pertanyaan (Rustaman, 2005).

Kegiatan praktikum yang dilaksanakan digunakan untuk mengaplikasikan teori yang dipelajari diperkuliahan. Observasi yang dilakukan peneliti pada praktikum di Jurusan Tadris Biologi, praktikum yang terjadi selama ini hanya untuk membuktikan kebenaran teori. Istilah "membuktikan" di sini bisa berpeluang membuktikan teori benar atau bisa jadi ada peluang teori salah. Praktikum juga menuntut mahasiswa untuk berpikir secara kreatif. Salah satu langkah untuk mengajarkan berpikir kreatif dan meningkatkan daya berpikir kreatif pada mahasiswa adalah memberikan ruang bagi para mahasiswa untuk mengekspresikan daya berpikir kreatif mereka (Wiwin Wulandari., Liliasari F.M., \& Titin Supriyanti., 2011).

Menurut Piaget (Sardiman, 2011)," menerangkan bahwa seseorang anak itu berpikir sepanjang berbuat, tanpa perbuatan berarti anak tidak berpikir." Oleh karena itu, agar anak berpikir sendiri maka harus diberi kesempatan untuk berbuat sendiri, berpikir pada taraf verbal baru akan timbul setelah anak itu berpikir taraf perbuatan. Bahwa aktivitas dalam arti luas, baik yang bersifat fisik/jasmani maupun mental/rohani. Kaitan keduanya akan menumbuhkan aktivitas belajar yang optimal. Anak mengerjakan sendiri dapat dilakukan dengan praktikum.

Kegiatan praktikum merupakan bagian dari proses pembelajaran Biologi. Kegiatan laboratorium dapat membuat konsep yang semula abstrak menjadi konkret dan semakin mudah untuk dipelajari. Selain itu kegiatan praktikum dapat melatih siswa berpikir ilmiah dan kreatif, melalui observasi, mengumpulkan dan menganalisa data, serta memecahkan suatu permasalahan. Dengan melakukan praktikum dilaboratorium siswa dapat menemukan fakta sendiri dengan inderanya serta dapat mengaitkan 
pengalaman yang penuh dengan lambang-lambang dan hitungan yang diperoleh dalam proses pembelajaran (Altun et al, 2009).

Salah satu mata kuliah yang dipraktikumkan adalah Botany phanerogamae. Botany phanerogamae merupakan kajian mengenai dunia tumbuhan dan merupakan mata kuliah yang menuntut kegiatan praktikum pada peserta didik calon guru biologi di perguruan tinggi. Kegiatan praktikum botany phanerogamae merupakan suatu pembelajaran yang dapat meningkatkan dan mengembangkan keterampilan proses sains peserta didik khususnya calon guru biologi (Hadiansah, 2017).

Berdasarkan pengamatan peneliti pada praktikum Botany phanerogamae terdapat beberapa kendala. Salah satunya kurangnya sarana dan prasarana, dosen pengampu yang jarang mengotrol praktikum serta kurangnya asisten praktikum. Dari kendala yang ditemukan tersebut, maka perlu kiranya dilakukan evaluasi secara menyeluruh terhadap pelaksanaan praktikum yang diselenggarakan di Jurusan Tadris Biologi IAIN Kerinci, sehingga penyelenggaraan praktikum nantinya dapat semakin dioptimalkan.

Salah satu cara yang di lakukan untuk memaksimalkan fungsi praktikum Botany phanerogamae adalah melalui evaluasi program praktikum. Stufflebeam dan Shinkfield mendefinisikan evaluasi "evaluation is the systematic assessment of the worth or merit of anobject". Dapat diartikan bahwa evaluasi adalah penilaian sistematis terhadap nilai atau kelebihan suatu objek (Stufflebeam dan Shinkfield, 2007). Yarbroug juga mengutip defined evaluation as the "systematic investigation of the worth or merit of an object". Dapat diartikan bahwa evaluasi sebagai penyelidikan sistematis nilai atau manfaat dari sebuah objek (Yarbrough-Donald B., dkk 2010). Menurut Wayan Nurkancara dan P.P.N. Sumartana evaluasi pendidikan dapat diartikan sebagai tindakan atau suatu proses untuk menentukan nilai sebagai sesuatu dalam dunia pendidikan atau segala sesuatu yang ada hubungannya dengan dunia pendidikan (Djamarah-Syaiful Bahri dan Zein-Aswan., 2014). Dengan kata lain setiap kegiatan yang terdapat dalam dunia pendidikan baik itu berupa sains ataupun ilmu sosial harus disertai dengan evaluasi untuk melihat sejauh mana kemampuan yang terdapat pada kegiatan tersebut.

Ada banyak model evaluasi program yang di rancang oleh para ahli, Modelmodel tersebut cenderung dikembangkan sesuai dengan tujuan pelaksanaan evaluasi salah satunya adalah Model evaluasi program CSE-UCLA. Menurut Arikunto CSE- 
UCLA merupakan singkatan dari dua bagian, yaitu CSE dan UCLA. CSE adalah singkatan dari Center for the Study of Evaluation, sedangkan UCLA adalah singkatan dari University of California in Los Angeles. CSE-UCLA Evaluation Model dikembangkan oleh Alkin menekankan pada lima tahap yang dilakukan, yaitu: System Asessment, Program Planning, Program Implementation, Program Improvement dan Program Certification (Ashiong P. Munthe, 2015; Divayana dan Sugiharni, 2016) .

Model evaluasi CSE-UCLA ini tidak pernah digunakan untuk mengevaluasi praktikum. Model evaluasi CSE-UCLA banyak digunakan untuk mengevaluasi suatu program. Hal ini sesuai dengan pernyataan Divayana \& Sugiharni (2016) yang menyatakan bahwa "Evaluasi merupakan suatu kegiatan untuk mengumpulkan, memahami, dan melaporkan hasil analisis tentang suatu program/objek tertentu sehingga hasilnya dapat digunakan untuk pertimbangan dalam mengambil suatu keputusan apakah program tersebut dilanjutkan ataukah dihentikan”. Peneliti memilih model ini karena model evaluasi ini merupakan model evaluasi yang komprehensif dengan langkah-langkah evaluasi yang sistematis dan paling riil. Pertimbangan lain adalah karena praktikum Botany phanerogemae juga merupakan suatu program yang ada jurusan Tadris Biologi yang harus dievaluasi.

Bertitik tolak dari fenomena tersebut, maka peneliti tertarik untuk melakukan penelitian dengaan judul "Evaluasi Praktikum dengan Menggunakan Model CSEUCLA (Studi pada Mahasiswa Jurusan Tadris Biologi Institut Agama Islam Negeri Kerinci)".

\section{METODOLOGI PENELITIAN}

Penelitian ini termasuk kedalam kategori penelitian kualitatif yang termasuk jenis metode studi kasus (case study). Creswell mendefinisikan studi kasus sebagai eksplorasi dari sistem-sistem yang terkait (bounded system) atau kasus. Suatu kasus menarik untuk diteliti karena corak khas kasus tersebut yang memiliki arti pada orang lain, minimal bagi peneliti (J.R.Raco, 2010).

Teknik pengumpul data (1). Pengamatan (Observasi): observasi pelaksanaan praktikum Botany Phanerogamae yang dilakukan di Laboratorium Tadris Biologi Institut Agama Islam Negeri Kerinci. (2). Wawancara (Interview): merupakan wawancara semi terstruktur. Wawancara ini dimulai dari isu yang dicakup dalam pedoman wawancara. Penentuan informan dalam penelitian ini menggunakan teknik 
purposive sampling, yaitu informan yang berkompeten dan mempunyai relevansi dengan penelitian yang terdiri dari etua jurusan satu orang, dosen pengampu dua orang, Asisten praktikum dua orang dan mahasiswa tujuh orang. (3). Dokumentasi: Peneliti mencari data yang diperlukan sebagai penunjang kevalidan akan penelitian seperti data tentang visi dan misi Jurusan Tadris Biologi Institut Agama Islam Negeri Kerinci, kerangka kualifikasi nasional indonesia Jurusan Tadris Biologi, tujuan praktikum yang terdapat di dalam penuntun praktikum Botany Phanerogamae, dan struktur organisasi Jurusan Tadris Biologi.

Teknik Analisis data disebut juga pengolahan data dan penafsiran data. Penganalisaan dalam bentuk kualitatif penulis akan menggunakan analisa teksinomis yaitu fokus penelitian ditetapkan terbatas pada domain tertentu yang sangat berguna dalam upaya mendeskripsikan atau menjelaskan fonomena-fenomena yang menjadi sasaran semua penelitian. Analisa data adalah proses mengelompokkan dan mengurutkan data ke dalam pola, kategori, dan satuan uraian dasar sehingga dapat ditemukan tema dan dapat dirumuskan hipotensi kerja seperti yang didasarkan oleh data. Setelah berakhirnya pengumpulan data yang diinginkan maka data yang telah terkumpul, akan penulis analisa dengan menggunakan analisa kualitatif. Selanjutnya dalam pemakaian pola pikir, maka penulis menggunakan pola Komparatif (Yasni Efyanti, 2007). Dalam pelaksanaan penelitian, analisis data dapat dilakukan bersama proses pengamatan. Jadi selama proses penelitian berlangsung data yang diperoleh dapat langsung dianalisis. Untuk mempermudah dalam menganalisa data yang peneliti peroleh melalui teknik terakhir ini, maka data yang sifatnya keterangan, penulis analisa dengan menggunakan metode kualitatif dengan berdasarkan pola pikir komparatif (Riduwan, 2009).

Teknik keabsahan data menggunakan Triangulasi. Triangulasi adalah metode yang digunakan untuk mengecek keabsahan data, atau mengecek keabsahan temuan penelitian.

\section{HASIL DAN PEMBAHASAN}

Sistem Assesment Praktikum Botany Phanerogamae Mahasiswa jurusan Tadris Biologi IAIN Kerinci

Berhubungan dengan SistemAssesment atau program penilaian terhadap praktikum Botany Phanerogamae didapatkan hasil dari Kerangka Kualifikasi Nasional 
Indonesia beserta Profil Jurusan Tadris Biologi, Penuntun Praktikum Botany Phanerogamae dan Observasi.

Visi dan Misi Jurusan; Melihat Visi dan Misi Jurusan dan Kerangka Kuailifikasi Nasional Indonesia dapat disimpulkan bahwa hubungan antara Visi dan Misi Jurusan dengan Kerangka Kualifikasi Nasional Indonesia sangatlah sejalan. Yang mana aplikasi bidang keahlian mahasiswa, ilmu pengetahuan, teknologi, dan seni dapat diterapkan mahasiswa pada pendidikan dan pengajaran, lebih fokusnya pada pelaksanaan praktikum. Yang mana praktikum sebagai wujud praktek teori yang didapatkan mahasiswa di dalam perkuliahan. Begitu pula dengan adaptasi mahasiswa terhadap situasi yang dihadapi, dapat diterapkan oleh mahasiswa di masyarakat, yang mana mahasiswa tidak hanya di tuntut pintar tapi juga mampu beradaptasi dengan lingkungan masyarakat.

Tujuan Praktikum Botany Phanerogamae Tim Penyusun Praktikum Biologi, (2018); Berdasarkan Visi dan Misi Jurusan Tadris Biologi serta semua tujuan praktikum Botany Pahanerogamae, peneliti dapat menyimpulkan bahwa sejalannya antara Visi dan Misi dengan tujuan praktikum Botany Phanerogamae, dimana poin-poin Visi dan Misi sudah dijalankan oleh Jurusan Tadris Biologi, seperti: 1. Berkarakter Islami, yang mana pada pihak Institut Agama Islam Negeri Kerinci sudah menetapkan hal-hal yang harus dilaksanakan sesuai dengan Kaidah Agama Islam. 2. Berkualitas dan Berintegritas, seperti pelaksanaan praktikum, dengan adanya praktikum menambah kualitas dan juga mutu ilmu yang diperoleh mahasiswa melalui teori-teori yang telah di ajarkan. "Kegiatan praktikum sebagai proses pembelajaran sudah menjadi tuntutan pendidikan di semua jenjang pendidika yang mengajarkan biologi, sehingga dapat membantu mahasiswa memahami Biologi secara baik dan mengembangkan sikap ilmiah" (Pramadi, 2010). 3. Berwawasan global, yang mana pada pembelajaran ilmu tumbuhan dapat membawa pemikiran mahasiswa yang global, tidak terfokus pada satu daerah, akan tetapi wawasan yang global akan keanekaragaman hayati. 4. Integratif, memiliki satu tujuan agar dapat lebih memahami keanekaragaman tumbuhan maupun hewan secara biologis, dan 5. Berbasis kearifan lokal ekowisata, dengan adanya praktikum Botany Phanerogamae, mahasiswa bisa membudayakan tumbuhantumbuhan, setidaknya apapun yang menjadi bahan praktikum akan mudah di jumpai. 
Kebutuhan Sumber Daya Manusia, adapun sumber daya manusia yang di butuhkan pada pelaksanaan praktikum Botany Phanerogamae adalah dosen pengampu mata kuliah Botany Phanerogamae, dan asisten praktikum. Yang mana dosen pengampu sebagai penyampai teori-teori yang terkait pada pelaksanaan praktikum, sedangkan asisten dosen bertugas sebagai pemandu praktikum dan interaktif dengan mahasiswa atau praktikan, selain itu asisten dosen juga harus memiliki strategi dan keterampilan yang baik agar praktikum dapat berjalan dengan efektif.

Kedua kebutuhan sumber daya manusia tersebut haruslah terpenuhi dalam pelaksanaan praktikum Botany Phanerogamae, yang mana kalau salah satu sumber daya manusia tersebut tidak terpenuhi maka proses pelaksanaan praktikum tidaklah efektif dilaksanakan. Sehingga mahasiswa sebagai peserta praktikum juga memiliki kemampuan yang baik. Keterampilan proses sains yang dituntut untuk dimiliki dan dikembangkan oleh mahasiswa dalam mengembangkan kemampuan berpikirnya, yaitu: 1) merencanakan percobaan, 2) melakukan pengamatan atau observasi, 3) mengelompokkan atau klasifikasi, 4) menafsirkan atau interpretasi, 5) me-ramalkan atau prediksi, 6) mengajukan pertanyaan, 7) berhipotesis, 8) merencanakan percobaan, 9) menggunakan alat atau bahan, 10) menerapkan konsep, dan 11) berkomunikasi (Rustaman, dkk. 2005).

Dukungan partisipasi dari pihak terkait sangat diperlukan agar praktikum bisa berjalan. Seperti dengan adanya bantuan sarana prasarana dan operasional pada pelaksanaan praktikum. Jika dilihat dari kondisi laboratorium, wujud dukungan dan partisipasi dari pihak Institut Agama Islam Negeri Kerinci masih kurang. Laboratorium yang baik harus dilengkapi dengan berbagai fasilitas serta teknisi laboran yang berkompeten untuk memudahkan penggunaan laboratorium dalam kegiatan praktikum. Fasilitas tersebut diantaranya berupa fasilitas umum dan khusus. Fasilitas umum merupakan fasilitas yang dapat digunakan oleh semua pengguna laboratorium seperti: penerangan, ventilasi, air, bak cuci, aliran listrik dan gas. Fasilitas khusus berupa peralatan lainnya seperti meja peserta didik, meja guru, kursi, papan tulis, lemari/rak alat, lemari bahan, ruang timbang, lemari asam, perlengkapan P3K, pemadam kebakaran, simbol-simbol bahan kimia serta tanda-tanda peringatan keselamatan kerja (Putri Agustina \& Ike Wartini Ningsih. 2017). Namun pada kenyataannya standar laboratorium yang baik belum sepenuhnya terpenuhi. 
Landasan Hukum, pada pelaksanaan praktikum Botany Phanerogamae yang di programkan oleh pihak Jurusan Tadris Biologi Institus Agama Islam Negeri Kerinci memiliki Landasan Hukum yang terdapat pada Kerangka Kualifikasi Nasional Indonesia atau KKNI. Yang mana pada dokumen tersebut didapatkan capaian pembelajaran keterampilan khusus jurusan. Setelah melihat landasan hukum yang terdapat pada Kerangka Kualifikasi Nasional Indonesia dapat dikatakan bahwa baik itu Visi dan Misi Jurusan, tujuan praktikum Botany Phanerogamae sangat sejalan sesuai dengan landasan hukum yang ada seperti Pelestarian Lingkungan. Dengan adanya praktikum Botany Phanerogamae, mahasiswa akan mengerti tentang organ generatif dan organ vegetatif dari tumbuhan, sehingga dapat mewujudkan Pelestarian Keanekaragaman Hayati dilingkungan Institut Agama Islam Negeri Kerinci maupun di lingkungan masing-masing.

Dari hasil studi dokumen dan observasi peneliti diatas dapat disimpulkan bahwa, proses pelaksanaan praktikum Botany Phanerogamae di Jurusan Tadris Biologi Institut Agama Islam Negeri Kerinci sudah terlaksana dengan baik. Namun mempunyai kendala pada poin visi dari Jurusan Tadris Biologi dan juga dari Kerangka Kualifikasi Nasional Indonesia belumlah terwujud "Interkoneksi Ekowisata" dan " Kelestarian Lingkungan dan Sumber Daya Alam", yang mana kepedulian mahasiswa terhadap lingkungan ataupun penanaman tanaman di lingkungan Jurusan Tadris Biologi sangatlah minim dilakukan, sehingga akan berdampak buruk bagi pelaksanaan praktikum khususnya pada praktikum Botany Phanerogamae, dimana bahan praktikum yang seharusnya akan mudah ditemui akan menjadi sulit untuk ditemui dan memerlukan waktu untuk menemukan tumbuhan yang diinginkan.

\section{Program Planning Praktikum Botany Phanerogamae Mahasiswa jurusan Tadris Biologi IAIN Kerinci}

Berhubungan dengan Program Planning atau tahap perencanaan terhadap praktikum Botany Phanerogamae didapatkan hasil dari study dokument dan hasil wawancara Ketua Jurusan TadrisBiologi, dosen pengampu Botany Phanerogamae, asisten dosen, dan mahasiswa.

Struktur Organisasi Jurusan Tadris Biologi; sebuah program atau organisasi belum lah lengkap sebelum adanya Struktur Organisasi, karena struktur organisasi sebagai sebuah acuan dalam melaksanakan tugas dari setiap anggota. Dari Struktur 
Organisasi yang ada di jurusan tadris Biologi dapat di lihat bahwa perekrutan dosen pada Jurusan Tadris Biologi sudah sesuai dengan latar belakang pendidikan dosen tersebut. Dan juga dapat dilihat dosen dengan latar belakang jurusan biologi lebih dominan, karena pelaksanaan pembelajaran pada Jurusan Tadris Biologi memang lebih terfokus pada pembelajaran ilmu biologi beserta cabang-cabang ilmu biologi tersebut.

Kesiapan kemampuan Dosen, Asisten dan Mahasiswa juga Tim Pengelola; Pada tahap perencanaan praktikum Botany Phanerogamae, peneliti melihat kesiapan dosen pengampu, asisten dosen, mahasiswa dan tim pengelola terjadinya komunikasi serta kerjasama yang baik agar proses jalannya praktikum juga berlangsung dengan baik. Kesiapan dosen pengampu, asisten dosen, mahasiswa, dan tim pengelola dapat kita ketahui dari pihak bersangkutan.

Setelah melihat hasil wawancara peneliti terhadap dosen, asisten dan mahasiswa serta Ketua Jurusan Tadris Biologi dapat disimpulkan bahwa, struktur organisasi, kesiapan dosen pengampu, asisten dosen, dan mahasiswa, kesiapan tim pengelola dapat dikatakan siap, karena sesuai dengan harapan jurusan seperti sinkronnya antara latar belakang pendidikan dosen pengampu sesuai dengan keahlian dosen tersebut, pemilihan asisten dosen yang di seleksi oleh pihak jurusan dengan beberapa tahap agar terpilihnya asisten yang berkualitas, serta persiapannya pun dilakukan secara objektif, demi keefektifan dalam pelaksanaan praktikum Botany Phanerogamae.

Kesiapan Sarana dan Prasarana; Sarana dan Prasarana praktikum merupakan salah satu hal yang penting di dalam pelaksanaan praktikum. Melakukan percobaan dalam sains membutuhkan alat dan bahan. "Berhasilnya suatu percobaan kerapkali tergantung pada kemampuan memilih dan menggunakan alat yang tepat secara efektif. Pengalaman menggunakan alat dan bahan merupakan pengalaman konkrit yang dibutuhkan mahasiswa untuk menerima gagasan-gagasan baru. Suatu syarat penting dalam belajar bagi mahasiswa yang masih pada tingkat operasional konkrit itu" (SusiwiAchmad, A-Hinduan, Liliasari \& Sadijah-Ahmad, 2009). Akan tetapi setelah semua kesiapan yang dibahas oleh peneliti mendapat kendala pada kesiapan sarana dan prasarana dalam pelaksanaan praktikum. Yang mana pada Laboratorium Tadris Biologi belum mempunyai oven, namun untuk membuat herbarium bisa dijemur di bawah terik matahari. Alat laboratorium juga ada beberapa yang telah rusak, seperti mikroskop, namun dapat diatasi dengan menggunakan mikroskop yang masih bagus. 
Kekurangan sarana dan prasarana yang ada di laboratorium bukanlah hal yang melemahkan bagi praktikan atau mahasisiwa, hal tersebut tidaklah mengurangi semangat dan keefektifan dari pelaksanaan praktikum Botany Phanerogamae, dengan alat dan bahan yang serba bercukupan bisa menjadi batu loncatan dan bahan perhatian dari Institut Agama Islam Negeri Kerinci.

\section{Program Implementation Praktikum Botany Phanerogamae pada Mahasiswa Jurusan Tadris iologi IAIN Kerinci}

Pada setiap proses praktikum, sosialisasi atau asistensi sebelum praktikum dilaksanakan sangatlah diperlukan, karena tanpa ada sosialisasi mahasiswa atau praktikan akan merasa bingung tentang apa-apa saja yang harus dilakukan pada pelaksanaan praktikum.

Sosialisasi Praktikum bagi Mahasiswa; Sosialisasi adalah proses sosial yang terjadi dalam diri seseorang dalam menyesuaikan diri dengan lingkungannya. Dengan kata lain, Sosialisasi praktikum bagi mahasiswa bertujuan agar mahasiswa mengerti apa-apa saja penyesuaian yang harus dilakukan pada saat praktikum. Dari hasil wawancara yang telah dilaksankan, dapat disimpulkan bahwasanya asistensi untuk mahasiswa dilaksanakan oleh asisten praktikum, yang mana asistensi memberikan sedikit wawasan tentang apa saja yang akan dipraktikumkan pada mata kuliah Botany Phanerogamae dan sekaligus pembagian kelompok perlokal untuk pelaksanaan praktikum. Hal ini berdampak positif bagi praktikan, karena pada saat praktikum tidak ada lagi kendala terhadap kelompok praktikum, sehingga nantinya praktikum bisa langsung dilaksankan. Kegiatan asistensi bertujuan agar mahasaswa benar-benar paham dengan materi yang akan dipraktikumkan.

Asistensi untuk asisten; Sebelum praktikum berlangsung akan ada asistensi untuk asisten praktikum. Asisten praktikum diberikan ilmu untuk menambah wawasan oleh dosen pengampu tentang bagaimana tata cara dan prosedur praktikum, sehingga waktu mereka memandu praktikum, mereka sudah diperkaya oleh ilmu-ilmu yang diberikan oleh dosen pengampu.

Program Improvement Praktikum Botany Phanerogamae pada Mahasiswa Jurusan Tadris Biologi IAIN Kerinci

Berhubungan dengan Program Improvement atau tahapan pelaksanaan terhadap praktikum Botany Phanerogamae didapatkan hasil dari observasi dan wawancara 
bersama asisten dosen dan mahasiswa atau praktikan. Berdasarkan hasil observasi tentang pelaksanaan praktikum Botany Phanerogamae peneliti di Laboratorium Jurusan Tadris Biologi sudah terbilang efektif, baik dalam penyampaian materi dari asisten dosen maupun respon mahasiswa selama praktikum Botany Phanerogamae berlangsung. Sehingga interaksi antara praktikan dan asisten dosen berjalan dengan baik, tentunya akan berdampak positif bagi pengetahuan praktikan tentang apa saja materi yang disampaikan oleh asisten dosen.

Berdasarkan hasil wawancara yang telah dilaksanakan, dapat disimpulkan bahwa keberadaan praktikum Botany Phanerogamae di Jurusan Tadris Biologi Institut Agama Islam Negeri Kerinci memang sudah dilaksanakan sesuai dengan aturan yang ada, yang mana untuk mencerdaskan mahasiswa tidak bisa hanya teori-teori saja, tetapi harus di imbangi dengan praktek di lapangan. Sehingga apapun yang disampaikan pada tiap-tiap teori bisa lebih melekat dengan adanya keberadaan praktikum.

Namun terdapat kendala pada pelaksanaan praktikum Botany Phanerogamae, yang mana dari observasi yang telah peneliti lakukan sering kali dosen pengampu mata kuliah tidak terlihat pada pelaksanaan praktikum, sebaiknya hal tersebut tidaklah terjadi pada pelaksanaan praktikum, karena bisa berdampak buruk bagi praktikum, yang mana bisa terjadi kesenjangan antara teori yang telah disampaikan dosen pengampu mata kuliah Botany Phanerogamae dilokal dengan materi praktikum yang disampaikan oleh asisten dosen. Sehingga hasilnya akan berdampak negatif bagi mahasiswa atau praktikan.

Kurangnya keterampilan kerjasama juga terjadi di kalangan mahasiswa didukung oleh hasil penelitian (Rosita \& Leonard, 2013) bahwa keterampilan kerjasama mahasiswa dalam pembelajaran belum optimal karena mahasiswa akan cenderung individualistis, kurang bertoleransi, dan jauh dari nilai-nilai kebersamaan. Hal tersebut sependapat dengan hasil penelitian (Sholihah, 2016) bahwa kondisi yang memprihatinkan juga terjadi di kalangan mahasiswa yang memperlihatkan masih rendahnya keterampilan kerjasama diantara mereka, sehingga untuk mempersiapkan generasi yang lebih baik dan berkarakter serta yang mempunyai keterampilan kerjasama harus disiapkan melalui sebuah pendidikan. Hasil penelitian Suhardi, (2013) menyatakan bahwa keterampilan kerjasama mahasiswa dalam mengikuti proses pembelajaran biologi masih rendah, belum dikembangkan oleh dosen secara optimal. 
Sementara menurut Roshayanti, (2012) Pada umumnya pembelajaran Biologi di kelas lebih menekankan pada kerja praktik daripada melibatkan mahasiswa dalam proses berpikir.

\section{Program Certification Praktikum Botany Phanerogamae pada Mahasiswa Jurusan Tadris iologi IAIN Kerinci}

Ketercapaian Tujuan Praktikum oleh Praktikan; Ketercapaian semua tujuan dari paraktikum Botany Phanerogamae adalah hal yang paling diharapkan dari Jurusan Tadris Biologi Institut Agama Islam Negeri Kerinci. Dari hasil wawancara yang telah dilaksanakan dapat disimpulkan bahwa tujuan praktikum pada tiap-tiap praktikum sudah tercapai, dimulai dari praktikum pertama sampai praktikum ke delapan. Ketercapaian ini tentu yang lebih berperan adalah dosen pengampu Botany Phanerogamae dan juga asisten praktikum, karena tercapai atau tidaknya tujuan praktikum tergantung dari penyampaian materi dari dosen pengampu dan asisten praktikum. Sehingga setelah praktikum selesai, mahasiswa bisa berpikir lebih keatif. Awaludin (2007) juga menyatakan berpikir kreatif merupakan kemampuan dalam menyelesaikan masalah dan mengembangkan ide-ide dengan cara yang berbeda. Oleh karena itu, berpikir kreatif perlu diterapkan dalam setiap kegiatan proses ilmiah agar mahasiswa dapat menentukan cara terbaik untuk mengemukakan penemuan dan penjelasan mereka.

Respon mahasiswa terhadap praktikum; Dari hasil wawancara Asisten dosen dan mahasiswa, dapat disimpulkan bahwa ketercapaian tujuan Praktikum Botany Phanerogamaesudah tercapai di Jurusan Tadris Biologi, yang mana selain tercapainya tujuan Praktikum Botany Phanerogamae tersebut respon mahasiswa terhadap Praktikum Botany Phanerogamaejuga sangat positif dan mereka termotivasi untuk melaksanakan praktikum sehingga memicu suasana praktikum yang lebih efektif di Laboratorium Tadris Biologi Institut Agama Islam Negeri Kerinci. Sesuai dengan teori law of effect dari Thorndike dalam Sardiman (2011) yang menyatakan bahwa motivasi akan bertambah apabila belajar disertai rasa senang dan puas.

\section{SIMPULAN}

Berdasarkan hasil dan pembahasan maka dapat disimpulkan (1) Pada tahapan System assesment ini, poin-poin penilaian tersebut sudah dimiliki dan 
dilaksanakan, walaupun terdapat kendala pada kurangnya perhatian mahasiswa. (2) Program Planning, pelaksanaan praktikum dengan kategori siap, walaupun masih ada hal-hal yang harus dilengkapi tetapi itu bukanlah menjadi alasan malas untuk belajar, tetapi itu sebagai motivasi untuk semua pihak terkait agar masalah ini dapat diatasi dan pihak Institut Agama Islam Negeri Kerinci dapat lebih memperhatikan kondisi Laboratorium Tadris Biologi. (3) Program Implementation, penyampaian sosialiasi atau asistensi ini harus dilakukan secara berantai dari dosen pengampu sampai ke mahasiswa atau praktikan. (4) Program Improvement, pelaksanaan praktikum Botany Phanerogamae sudah dikategorikan efektif. (5) Program Certification, tahapan pelaksanaan praktikum bisa berjalan dengan efektif dan sesuai dengan yang diharapkan Jurusan Tadris Biologi Institut Agama Islam Negeri Kerinci.

\section{DAFTAR PUSTAKA}

Altun, E., Barış. D., Burak. F., Alev. A., İlker. Ç., (2009), Develoving an InteractIve Virtual Chemistry Laboratory Enrich With Contructivist Learning Activities For Secondary School, Procedia Social and Behavioral Sciences 1: 1895-1898.

Divayana, Dewa Gede H. dan Gusti Ayu Dessy S. (2016). Evaluasi Program Sertifikasi Komputer pada Universitas Teknologi Indonesia menggunakan Model CSEUCLA. Jurnal Pendidikan Indonesia, ISSN: 2303-288X, Vol. 5, No. 2. (https://scholar.google.co.id/citations?view_op=view_citation \&hl =en\&oe=ASCII\&user, diakses: 12 Agustus 2018).

Divayana, D.G.H. (2017) Evaluasi Pelaksanaan Blended Learning di SMK TI Udayanana menggunakan Model CSE-UCLA. Jurnal Pendidikan Vokasi Volume 7 No. 1, Februari 2017. https://www.e-jurnal.com/2017/04/ evaluasipelaksanaan-blended-learning.html, diakses: 12 Agustus 2018).

Djamarah, Syaiful Bahri \& Aswan Zein. (2014). Strategi Belajar Mengajar. Jakarta: PT. Rineka Cipta

Efyanti, Yasni. (2007). Bimbingan Skripsi Mahasiswa Stain Kerinci. STAIN Kerinci

Hadiansah. (2017). Pembelajaran Guided Inquiry Dalam Meningkatkan Keterampilan Proses Sains Calon Guru Pada Mata Kuliah Botani Phanerogamae. Jurnal Pendidikan dan Biologi Quagga, Vol.9 No.01 2017. (https://journal.uniku.ac.id/index.php/ quagga/article/view/508/399, diakses 02 Oktober 2018).

Imam Gunawan. (2013). Metode Penelitian Kualitatif. Jakarta : Bumi Aksara.

J.R.Raco. (2010). Metode Penelitian Kualitatif Jenis, Karakteristik, dan Keunggulannya.Jakarta : PT.Gramedia Widiasarana Indonesia.

Mannan, Endang Fitriyah. (2010). Resistensi Pustakawan. FIB UI

Munthe, Ashiong, P. (2015). Pentingnya Evaluasi Program di Institusi Pendidikan. Scholaria, Vol.5.No.2. Mei 2015 
Pramadi. R.A. (2010). Phanerogamae Sistem Cronquist dan APG. Pendidikan Biologi Jur PMIPA FTK UIN SGD Bandung.

Putri Agustina \& Ike Wartini Ningsih. (2017). Observasi Pelaksanaan Praktikum Biologi di Kelas XI SMA Muhammadiyah 1 Surakarta T.A. 2015/2016 Ditinjau dari Standar Pelaksanaan Praktikum Biologi, Bioeducation Journal Vol.I No.1, Maret 2017.

Riduwan. (2009). Belajar Mudah Penelitian. Bandung : Alfabeta.

Rosita, I., dan Leonard. (2013). Meningkatkan kerjasama siswa melalui pembelajaran kooperatif tipe think pair share. Jurnal Formatif, 3(1), 1-10.

Rustaman, A. (2005). Pengembangan Kompetensi (Pengetahuan, Keterampilan, Sikap dan Nilai melalui Kegiatan Praktikum Biologi. Penelitian Jurusan Pendidikan Biologi FPMIPA UPI Bandung.

Rustaman, N. (2006). Strategi Belajar Mengajar Biologi. Malang:UM Press

Sardiman. (2011). Interaksi dan Motivasi Belajar Mengajar. tersedia [online] di http://jurnal.upi.edu/file/ Euis_Yuniastuti.pdf, diakse 21 Juli 2018]

Sardiman. (2011). Interaksi dan Motivasi Belajar Mengajar. Jakarta: PT Raja Grafindo Persada.

Sholihah. (2016). Profil Kemampuan Kerjasama Siswa Dalam Pembelajaran Ipa. Lampung: Universitas Lampung.

Suhardi. (2013). Peningkatan Partisipasi Dan Kerjasama Siswa Menggunakan Model Kooperatif Tipe Jigsaw Pada Materi Protozoa Kelas X Sma Negeri pengasih. Jurnal Pendidikan Matematika dan Sains, 140-146.

Stufflebeam \& Shinkfield. (2007). The Joint Committee's

Susiwi, Achmad A.Hinduan, Liliasari, Sadijah Ahmad. (2009). Analisis Keterampilan Proses Sains Siswa Sma Pada "Model Pembelajaran Praktikum D-E-H”. Jurnal Pengajaran MIPA, Vol. 14 No. 2 Oktober 2009 (http://journal.fpmipa.upi.edu/index.php/jpmipa/article/view/320/ 231, diakses 23 September 2018).

Wand, Edwin \& Gerald W.Brown. (1957). Essential of Education Evaluation. Paperback Import December.

Wiwin Wulandari, Liliasari, F.M. Titin Supriyanti, (2011). Problem Based Learning Untuk Meningkatkan Keterampilan Berpikir Kreatif Dan Penguasaan Konsep Siswa Pada Materi Larutan Penyangga. Jurnal Pengajaran MIPA, Vol. 16 No. 2 Oktober $2011 \quad$ (http://journal.fpmipa.upi. edu/index.php/jpmipa/article/view/239/154, diakses 20 September 2018).

Yarbrough, Donal B. Dkk. (2010). Joint Committee on Standart for Educational Evaluation. 